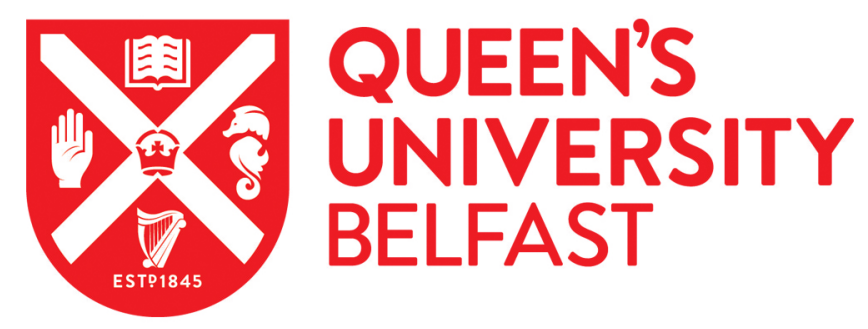

\title{
Pediatric pharmacokinetics of the antibiotics in the access and watch groups of the 2019 WHO model list of essential medicines for children: a systematic review
}

Rashed, A. N., Jackson, C., Gastine, S., Hsia, Y., Bielicki, J., Standing, J. F., Tomlin, S., \& Sharland, M. (2019). Pediatric pharmacokinetics of the antibiotics in the access and watch groups of the 2019 WHO model list of essential medicines for children: a systematic review. Expert review of clinical pharmacology, 12(12), 10991106. https://doi.org/10.1080/17512433.2019.1693257

Published in:

Expert review of clinical pharmacology

Document Version:

Peer reviewed version

Queen's University Belfast - Research Portal:

Link to publication record in Queen's University Belfast Research Portal

\footnotetext{
Publisher rights

Copyright 2019 Taylor \& Francis. This work is made available online in accordance with the publisher's policies. Please refer to any applicable terms of use of the publisher.
}

\section{General rights}

Copyright for the publications made accessible via the Queen's University Belfast Research Portal is retained by the author(s) and / or other copyright owners and it is a condition of accessing these publications that users recognise and abide by the legal requirements associated with these rights.

Take down policy

The Research Portal is Queen's institutional repository that provides access to Queen's research output. Every effort has been made to ensure that content in the Research Portal does not infringe any person's rights, or applicable UK laws. If you discover content in the Research Portal that you believe breaches copyright or violates any law, please contact openaccess@qub.ac.uk. 
2 Paediatric pharmacokinetics of the antibiotics in the Access and Watch groups of the

5 Asia N Rashed ${ }^{1,2^{*}}$ (https://orcid.org/0000-0003-1313-0915), Charlotte Jackson ${ }^{3}$, Silke 6 Gastine $^{3,4}$, Yingfen Hsia ${ }^{3,7}$, Julia Bielicki3,4, Joseph F Standing ${ }^{3,5,6}$, Stephen Tomlin ${ }^{6}$, Mike 7 Sharland ${ }^{3}$

8

1. Institute of Pharmaceutical Science, King's College London, London, UK

2. Pharmacy Department, Evelina London Children's Hospital, Guy's \& St Thomas NHS Foundation Trust, London, UK

3. Paediatric Infectious Diseases Research Group, Institute for Infection and Immunity, St George's, University of London, London, UK

4. Paediatric Pharmacology Group, University of Basel Children's Hospital, Basel, Switzerland

5. Great Ormond Street Institute of Child Health, University College London, London, UK

6. Pharmacy Department, Great Ormond Street Hospital for Children NHS Foundation Trust, London, UK

7. School of Pharmacy, Queen's University Belfast, Belfast, UK

\section{*Corresponding Author}

*Dr Asia Rashed

Research and Teaching Fellow

King's College London

London SE1 9NH

Email: asia.rashed@kcl.ac.uk

Tel: +442078484844 
Abstract

Introduction:

Pharmacokinetic-pharmacodynamic (PK-PD) studies of antibiotics in paediatrics are limited.

Paediatric dosing regimens for many antimicrobial drugs have been historically derived from adult pharmacokinetic data. Most paediatric formularies and dosing guidelines globally are expert based and provide no rationale for the recommended doses, leading to heterogeneous guidance.

Areas covered:

We systematically reviewed the current dosing for 28 antibiotics listed in the Access and Watch groups of the 2019 World Health Organisation (WHO) Essential Medicines List for children (EMLc). PubMed and EMBASE were searched for all PK-PD and pharmacological studies in paediatrics up to May 2018. In total, 262 paediatric related articles were deemed eligible. The most studied drugs were those where therapeutic drug monitoring is routine (aminoglycosides, glycopeptides) and study reporting detail was variable, with only $60.0 \%$ using the PK-PD results to make dosing recommendations. Based on this evidence, dose recommendations for each antibiotic were made.

Expert opinion:

We provide an up-to-date review of the limited available evidence on paediatric dosing for the 28 commonly prescribed antibiotics in the 2019 WHO EMLc. We propose synthesised dosing recommendations for those antibiotics administered systemically for the treatment of serious infections. Further PK-PD studies in children, particularly with underlying conditions, are needed.

Keywords:

Antibiotics; WHO; Access group; Watch group; EMLc; children; pharmacokinetics; pharmacodynamic; clinical pharmacology, systematic review 


\section{Article highlights:}

The proposed dosing recommendations quidance for antibiotics listed in the Access and Watch groups of the 2019 WHO EMLc can help to provide guidance for paediatric prescribers and policymakers.

- $\quad$ The PK-PD Eevidence base for the optimal dose for most commonly used antibiotics infections, is remarkably limited.

- We propose dosing guidance for antibiotics listed in the Access and Watch groups of the 2019 WHO EMLc to help to advise paediatric prescribers and policymakers.

- Given the limited PK-PD evidence identified, any guidance for antibiotic dosing needs to be regarded as interim until further higher quality evidence is available.

- These findings provide the basis for a future research prioritisation exercise to strengthen the evidence base for dosing of commonly used antibiotics in children.

- A more pioneering andFuture work should seek to develop effective and efficient methodselogy to assess PK-PD in children need to be undertaken as part of the strategic investigator-initiatedwithin clinical trials. 


\section{Introduction}

108 Antimicrobials are among the most commonly prescribed classes of drugs in children [1-6]. 109 However, paediatric dosing regimens for many antimicrobials have been historically derived 110 from pharmacokinetic (PK) data in adults and have been based on assumed linearity between 111 exposure and total body weight [1, 2]. This approach, although widely used in clinical practice, 112 lacks empiric evidence and may result in inappropriate systemic drug exposures of many 113 drugs in neonates and children [3, 4]. By providing rational dosing guidelines for a number of 114 agents, the Essential Medicines List for children (EMLC) was developed in part to address 115 these concerns [5].

117 To tackle emerging antimicrobial resistance and assist antibiotic stewardship, in 2017 the 118 WHO EML Antibiotic Working Group proposed to classify antibiotics into three groups: Access, 119 Watch, and Reserve, collectively known as the AWaRe classification and based on the drugs' 120 importance in treating common conditions, probability of resistance emerging, and affordability 121 [5-6]. The Access group contains generally narrower spectrum antibiotics recommended as 122 first and second choice for most common clinical infection syndromes. The Watch group

Several initiatives over the last two decades have led to the development of paediatric formularies [7-8]. However, at present, there are a limited number of paediatric formularies globally, including the USA "Red Book" [9], the European "Blue Book" [2], the British National Formulary for children (BNFc) [10] and the WHO Pocket Book of Hospital Care in Children [11]. The Red Book from the American Academy of Pediatrics, for example, provides guidance for 63 antibiotics, but does not provide any rationale behind the dosing recommendations. It is difficult for clinicians to determine whether the dose recommendations were derived from pharmaceutical summary of product characteristics, academic publications, historical practice, expert opinion or any combination of these sources. For example, the dosing guidance published in the Blue Book comes from a guidance committee considering and simplifying the recommendations from the BNFc, rather than from systematic evidence review.

Recently the Dutch Children's formulary has been developed [12] which aims to address some of the limitations in established formularies. The Dutch Children's formulary; provides evidence-based dosing recommendations with references, offering transparency on the evidence used. However, since it is written in Dutch, this may make it difficult to be adopted 
by other countries. The overall lack of standardized rationale in paediatric formularies has led to heterogeneous guidance which has the potential to cause confusion [13-14].

Pharmacokinetic-Pharmacodynamic (PK-PD) studies measure the drug concentrations reached in relevant tissues under specified dosing strategies. Together with data on clinical effectiveness and / or surrogates of effectiveness such as the relationship between PK-PD parameters (Cmax, AUC or time above $\mathrm{MIC}$ ) and the minimum inhibitory concentration (MIC) of expected pathogens [15], such studies can contribute to the evidence base for dosing recommendations and monitoring these concentrations over time (therapeutic drug monitoring, TDM).

This review aims to summarise the evidence base for the dosing regimens in neonates and children of commonly prescribed antibiotics in the Access and Watch groups of the 2019 WHO EMLc list based on the published PK-PD literature. This review has the potential to inform specific recommendations for the dosing guidance for antibiotics listed on EMLc.

\section{Methods}

The review was conducted and reported in accordance with the PRISMA guideline for systematic reviews and was registered on PROSPERO with registration number CRD42018094396.

\subsection{Literature search strategy}

A literature search using PubMed and EMBASE (from inception up to 31 May 2018) was conducted by one investigator (ANR) to identify studies describing the PK-PD of systemically administered antibiotics listed in the Access and Watch groups of the WHO modelEMLc 2019 [5]. This comprised all 19 antibiotics listed in the Access group and nine mostcommonly used antibiotics appearing in the Watch group (Supplementary Table 1) [16]. Separate searches were undertaken for each of the 28 antibiotics, with search terms relating to the international non-proprietary drug name, pharmacokinetics, neonatal and paediatric age groups and routes of administration (Supplementary Figure 1).

\subsection{Inclusion and exclusion criteria}

All studies reporting the PK-PD of one or more of the included drugs in children below the age of 18 years were included. Studies were limited to those reported in English using the language filter on the two databases, and no restrictions on year of publication were applied. Relevant studies were also identified from the reference lists of the included articles. 
Studies reporting topical route of administration, describing administration of drug in participants $>18$ years old, from which paediatric data could not be separated or administration of a related or precursor compound, that does not include dosing of the search drug were excluded. Animal and in-vitro studies, conference abstracts, letters, editorials and descriptive review articles, and clinical studies in which no PK-PD parameters or TDM were measured were also excluded. All search results were screened for eligibility by two reviewers (ANR, $\underline{\mathrm{CJ}}$, with disagreements resolved by discussion; if necessary, a third reviewer $(\mathrm{YH})$ was consulted.

\subsection{Data extraction}

Data were extracted from included articles by two reviewers (ANR, CJ) into a Microsoft Excel spreadsheet, with disagreements resolved as above. Data extracted from each study included information related to the reference, setting and participants, treated conditions (if reported), route of administration, dosing details, and authors' dose recommendations.

\subsection{Quality of evidence assessment}

There is currently no standard system for assessing the quality of PK-PD studies. Therefore, we adapted the grading system described in Barker et al. [17] to assess the quality of evidence. Each study was classified based on the quality of evidence as weak, intermediate or strong. This grading system is described in more detail in Gastine et al's study [EGAPPS (Grading and Assessment of Pharmacokinetic-Pharmacodynamic studies): Developing -a Gritical-critical Appraisal-appraisal System-system for antimicrobial PK-PD studies - Grading and Assessment of Pharmacokinetic-Pharmacodynamic development and application in pediatric antibiotic Studies; Expert Review of Clinical Pharmacology Journal 2019 submittedaccepted].

\subsection{Recommendations for new dosing guidance}

Considering the available literature, clinical experience, existing guidelines [2, 9-12], and the practical ease of administration, a panel of experts (consultant paediatrician, consultant paediatric pharmacist, paediatric pharmacokinetic expert, clinical paediatric research pharmacist) proposed new dosing guidance for antibiotics in the Access and Watch groups of WHO EMLC 2019. Our dosing recommendations were reviewed by the WHO EML Antibiotic Working Group and further amended based on their comments.

\subsection{Data analysis}


215 We carried out a narrative descriptive analysis due to the heterogeneity of the results between 216 studies.

\section{Results}

\subsection{Search results}

221 Our search, after removing duplicates, identified 589 articles (Figure 1). Of these, 345 were 222 potentially relevant and their full texts were assessed for eligibility, and 262 articles met the 223 inclusion criteria and were included in the review, with four of the studies includinged more 224 than one drug.

225 The included studies were published between 1967 and 2018 and the greatest number were 226 from the USA $(42 \%, 110 / 262$, Tables 1$)$.

227 The most studied antibiotic was gentamicin $(24 \%, 62 / 262)$, followed by vancomycin (18.3\%, $22848 / 262)$ and amikacin (8.4\%, 22/262). There were only three antibiotics for which no eligible studies where retrieved: nitrofurantoin, doxycycline, and spectinomycin.

\subsection{Route of administration} In $80.1 \%$ (210/262) of the studies antibiotic was given via intravenous (IV) route, in $10.3 \%$ $(27 / 262)$ studies the drug was given orally, and in $5.3 \%(14 / 262)$ of the studies the drug was administered intramuscularly (IM) (Table 2). The route of administration was not standardised: in $2 \%(5 / 262)$ of the studies the drug was administered either IM or IV, and in $2.3 \%(6 / 262)$ either IV or orally.

\subsection{Treated indications}

Overall, 55 indications were reported in 88.2\% (231/262) studies, with "proven or suspected infections" being the most common reported indication $(18.2 \%, 42 / 231)$, followed by "various infections" (13.0\%, 30/231) and sepsis (13.0\%, 30/231) (Supplementary table 2). Indications for treatment were not clearly stated in $12.0 \%$ (31/262) studies.

\subsection{Quality of evidence assessment} The strength of evidence was assessed as intermediate in $82.4 \%(216 / 262)$ of the studies and weak in $10.3 \%(27 / 262)$ studies. Only in $7.2 \%(19 / 262)$ of the studies, the strength of the evidence was considered strong; these studies were published between 2006 and 2018.

248 Further details on the quality of evidence are presented in the second study by Gastine et al 249 [GAPPS (Grading and Assessment of Pharmacokinetic-Pharmacodynamic studies): 250 Developing a Critical_critical Appraisal appraisal System-system for antimicrobial PK-PD 251 studies - Grading and Assessment of Pharmacokinetic-Pharmacodynamic development and 
252 application in pediatric Ss studies; Expert Review of Clinical Pharmacology Journal 2019 253 submittedaccepted].

\subsection{New dosing guidance recommendation}

256

257

258 More than half of the studies $(60.0 \%, 157 / 262)$ made dose recommendations (Supplementary table 2 ) based on their studies' findings, while in $40.1 \%$ (105/262) no dose recommendation was reported. Table 3 presents suggested new guidance for treatment (not prophylaxis) doses for common conditions via the oral or intravenous route.

\section{Discussion}

\subsection{Principal findings}

To our knowledge, this is the largest comprehensive systematic review on the PK-PD of antibiotics to date. In this review, we have been able to identify 262 PK-PD studies in children giving an up-to-date summary for the 25 out of the 28 -antibiotics listed in the Access and Watch groups of the 2019 WHO EMLc.

The studies identified in this review suggested that the PK-PD for commonly prescribed antibiotics have not been well established in children. There is very little PK-PD data on the relatively new antibiotics compared to older and thus more investigated antibiotics like gentamicin, vancomycin and amikacin. The included studies made a wide range of dosing recommendations, often based on limited evidence. By combining these with existing guidelines and clinical experience, the panel made suggestions for future dosing guidelines; however, the evidence base was generally intermediate in strength, and recommendations may change if future, robust studies suggest that this is appropriate.

Although this review found that the strength of the dosing recommendations in the majority of the included studies was rated to be intermediate, it is noticeable that the studies providing strong evidence were published recently, perhaps because PK-PD studies are now being conducted using appropriate, sophisticated analytical techniques [18]. There are multiple possible explanations for the otherwise weak evidence base. Low parental consent rates and ethical issues impede the involvement of children in PK-PD studies [19]. The use of innovative clinical trial design can overcome these obstacles; e.g. sparse and scavenged PK samples, and population PK techniques [20].

It is worth noting that this review started before the release of the updated WHO EMLc 2019. We initially started researching antibiotics listed in the Access group of the WHO EMLc 2017. In the initial AWaRe classification, the Access group included a total of 28 antibiotics; "Core 
access antibiotics" and selected antibiotics that are also listed in the Watch group. These selected Watch antibiotics are commonly used in clinical practice [16]. In the 2019 version, the EML Expert Committee made a clear separation between the AwaRe groups and the nine antibiotics that were listed in both Access and Watch groups are now only listed in the latter group [5]. Hence, two drugs (ceftazidime, cefuroxime) listed in the Watch group of the 2019 EMLc were not included in this review.

The heterogeneity in the reporting of PK-PD studies complicates synthesis of evidence from multiple studies, which may use very different analytical approaches and present different PK parameters. There is limited consensus on reporting paediatric PK-PD data [21-23]. Developing a consensus in paediatric population-PK reporting and meta-analytical methodsology for traditional and population studies would help to standardise reporting, aiding comparison and synthesis of study results.

It is acknowledged that there are widely varying dosing recommendations across countries. For example, dosing strategies may be weight-based (United States [9]), age-banded (United Kingdom [10]) or weight-banded (WHO [11]). These national preferences make it difficult for a single set of recommendations to be adopted worldwide.

Thus, considering the literature and the lack of harmony in the currently available international formularies, we have derived evidence-based dosing guidance (Table 3) for 28 antibiotics listed in the WHO EMLc 2019 and included in this review. These recommendations should be used as guidance for the treatment (not prophylaxis) of the most common conditions via oral or parenteral route of administration. Though these recommendations might help prescribers in devising treatment regimens, they are intended as guidance only and clinical evaluation of the patients should always be used to inform subsequent therapy.

\subsection{Strengths and limitations}

This is the most comprehensive review on paediatric dosing of 28 antibiotics included in the 2019 WHO EMLc. Hence, we were able to devise evidence-guided dosing recommendations guidance which was also assessed by an expert panel.

However, the limitations of this review must be considered when interpreting our findings. The heterogeneity among included studies precluded meta-analysis. In addition, though our search strategy and inclusion criteria were designed to be highly sensitive, some studies, especially unpublished, may have been missed. Studies not indexed in Embase or PubMed will have been omitted. Finally, we did not include studies published in languages other than English. 


\section{Conclusion}

328 We reviewed the available evidence base for 28 antibiotics listed in the Access and Watch groups of the WHO EMLc 2019. The variation in the reported parameters, the small sample sizes, and the outdated methods of analysis in a lot of the studies showed that paediatric PKPD for commonly prescribed antibiotics have not been well established.

Given the insufficient evidence for dosing of the widely used antibiotics included in this review, there is therefore a need for collaboration between paediatric pharmacokinetic researchers and clinical trial networks internationally to tackle the evidence gaps in a complementary and strategic manner. Where there are critical gaps, innovative and efficient approaches towards assessing PK-PD e.g. as part of strategic investigator-initiated trials should be undertaken. Furthermore, paediatric-specific PK-PD and dosing studies should generally be included as part of the licensing process for newly developed antibiotics such as third generation cephalosporins (e.g. cefixime).

\section{Expert opinion}

343 Further work beyond the scope of this review is needed to fully inform dosing recommendations. Firstly, formal methods of assessing the strength of evidence provided by PK studies are needed. This could build upon a proposed checklist for the reporting of clinical PK studies [23] as well as a proposed hierarchy of PK evidence [16], such as the GAPPS presented by Gastine et al [Developing a Critical Appraisal System for antimicrobial PK-PD studies - Grading and Assessment of PharmacokineticPharmacodynamic Studies; Expert Review of Clinical Pharmacology Journal 2019 submitted].

Secondly, clinical outcomes (including drug toxicity) should be considered. Full review of toxicity data would require inclusion of studies of clinical endpoints which were not eligible for this review of PK data, as well as a consensus on PD targets. A systematic review of adverse events in paediatric randomised controlled trials of antibiotics reported a median of $22.5 \%$ of children experienced an adverse event in 33 trials, but was not able to compare toxicity under different dosing regimens [24].

Thirdly, the duration of antibiotic treatment is an important factor to consider in guidelines. Together with the timing of switch from intravenous to oral treatment, duration of treatment has been reviewed for a range of paediatric infection syndromes, based on clinical 
outcome data [25]. As with dosing data, the evidence in this area is limited, but recommended total (intravenous plus oral) durations were typically between 7 and 14 days, depending on the condition. Shorter durations were recommended for communityacquired pneumonia ( 3 days if mild, $\leq 7$ days if moderate or severe uncomplicated), lower urinary tract infection (3-4 days) and meningococcal bacteraemia (4-5 days) [25]. Durations of several weeks were recommended for conditions including bacterial endocarditis, brain abscess and subdural empyema, lung abscess, and several musculoskeletal infections, where it takes time to build up the level in the target region.

There are an estimated 1.9 billion children in the world currently, around $27 \%$ of the total world population [26]. Children are frequently exposed to antibiotics in their early life. There is limited data on rates of prescribing for children in low-middle income country (LMIC) settings, but it is likely there are around 1-2 billion courses of antibiotics taken by children each year, by far the commonest medicine that children receive. The results of this review are therefore very disappointing in that for nearly all common infections, the optimal dose of antibiotic is still unknown. Indeed, the evidence base for the optimal choice of drug for most common infections, as well as for dose, duration and delivery/formulation is remarkably limited. Clearly much remains to be done. The WHO has made a good start by defining the most important "Access" and "Watch" antibiotics that are needed to treat the most common and serious infections. These two submitted papers [Rashed et al. 2019, Gastine et al. 2019] provide a framework that can be used to clarify where the gaps in evidence are and what studies need to be performed to improve the quality of prescribing through a more formal and reproducible process.

There remains a serious challenge in defining the "optimal" dose of any antibiotic given to a child. Previously, PK-PD exposure to target the commonest pathogens causing a specific clinical infection syndrome could be defined and dosing regimens derived based on maximising efficacy usually extrapolated from adult data. Also, despitealthough there are very few studies that are considered real PD studies, it is easier to extrapolate PD target for antibiotics compared to other drugs, because antimicrobials target-effect targets a microorganisms and not a physiological mechanism. More recently regulators have accepted that safety parameters can also be extrapolated from adult data for at least well-established classes of antibiotics [27]. The therapeutic index, which is used to compare the serum level of the therapeutically effective dose to the toxic dose of a drug, has been challenged recently with increasing rates of antimicrobial resistance in both high and LMICs. Standard dosing regimens for common antibiotics may no longer be adequate with steadily increasing minimum inhibitory concentrations (MICs) of common pathogens. Increasing exposure to try and 
combat this problem, such as increasing the dose to achieve higher Cmax, may in turn lead to increased toxicity. The balance will be to optimise dosing regimens as needed to maintain clinical outcomes, while keeping the risks of toxicity minimal. This adds complexity to dosing guidance, where optimal exposures may vary geographically due to varying rates of resistance between countries or regions. Further complexity is added by the need to alter dosing guidance for either a child who has complex underlying disease or is critically ill. Standard European Committee on Antimicrobial Susceptibility Testing (EUCAST) breakpoints for deriving optimal clinical outcomes from drug exposure are based virtually entirely on adult clinical outcome data [2728]. Higher antibiotic exposures may be required for children with developing or impaired immune systems, such as neonates or those with malnutrition, HIV or other complex underlying conditions. Neonates and children with severe infections, such as sepsis, may also have complex alterations in PK characteristics, including volume of distribution and excretion, such as augmented renal clearance. Historically the approach that has been taken is, for example in the UK, to double the dose in severe infection, but this may be inadequate in the context of severe and/or resistant infections.

The dosing of antibiotics needs to consider not only the child in front of the clinician now, but also the child yet to come. Inadequate dosing that selects for future resistance by failing to inhibit the growth of resistant mutants is a major issue when there is such a limited pipeline of future antibiotics. Dosing regimens need to consider exposure above the resistance inhibitory concentration as well as the MIC. As further work rapidly explores the impact of antibiotics on the young child's microbiome, it is also likely that dosing regimens will need to be explored that minimise this important potential adverse effect on children's health.

These are complex issues with many potentially conflicting influences on optimal dosing, some of which are highly specific to paediatrics. Future dosing guidance will need to be based not only on improved modelling, but also clinical outcomes established in well planned studies collecting data on the most important real-world endpoints, toxicity, selection of resistance and impact on the microbiome. Dosing regimens also need to consider the simplest reasonable formulations that can be produced at low cost and high quality so access to appropriate antibiotics can be enhanced and maintained for the poorest children. These considerations will need teams of experts and multiple stakeholders to provide explicit evidence-based recommendations that will need to be reviewed regularly as data emerge.

\section{Funding}

The review was funded by the World Health Organisation. 


\section{Declaration of interest}

ANR was funded by the WHO during this study. Other authors declare no conflict of interest.

\section{References}

1. Ahmed U, Spyridis $N$, Wong IC, et al. Dosing of oral penicillins in children: is big child=half an adult, small child=half a big child, baby=half a small child still the best we can do? Bmj 2011; 343:d7803.

2. Sharland M, Butler K, Cant A, et al editors. Manual of Childhood Infections: The Blue Book, $4^{\text {th }}$ ed. Oxford: OUP; 2016.

3. van den Anker JN. Getting the dose of vancomycin right in the neonate. Int J Clin Pharmacol Ther. 2011; 49(4):247-9.

4. Bartelink $\mathrm{IH}$, Wolfs $\mathrm{T}$, Jonker $\mathrm{M}$, et al. Highly variable plasma concentrations of voriconazole in pediatric hematopoietic stem cell transplantation patients. Antimicrob Agents Chemother. 2013; 57(1):235-40.

5. WHO. Excutive summary: the selection and use of essential medicines 2019. Report of the $22^{\text {nd }}$ WHO Expert Committee on the selection and use of essential medicines. [cited 25 July 2019] Availble from: https://apps.who.int/iris/bitstream/handle/10665/325773/WHO-MVP-EMP-IAU2019.05-eng.pdf? sequence=1\&isAllowed=y

6. Sharland M, Pulcini C, Harbarth S, et al. Classifying antibiotics in the WHO Essential Medicines List for optimal use-be AwaRe. Lancet Infect Dis. 2018; 18(1):18-20.

7. Lenney $\mathrm{W}$. The development of a national children's formulary. $\mathrm{Br} \mathrm{J}$ Clin Pharmacol. 2015; 79(3):441-5.

8. Hoppu K, Anabwani G, Garcia-Bournissen F, et al. The status of paediatric medicines initiatives around the world-What has happened and what has not? Eur $\mathrm{J}$ Clin Pharmacol. 2012; 68(1):1-10.

9. Kimberlin DW, Lond S, Brady MT, et al., editors. Red Book 2015: Report of the Committee on Infectious Diseases, 30 th ed. American Academy of Pediatrics; 2015.

10. National Institute for Health and Care Excellence. British National Formulary for Children. 2019. [Accessed 25 July 2019]; Available from: https://bnfc.nice.org.uk/.

11. World Health Organization. Pocket book of hospital care for children: Guidelines for the management of common illnesses with limited resources. 2005 [Accessed 25 July 2019]; Available from: http://www.who.int/maternal child adolescent/documents/9241546700/en/.

12. Kinderformularium. [Accessed 16 Aug 2019]; available from: www.kinderformularium.nl 
13. Pulcini C, Wencker F, Frimodt-Møller N, et al. European survey on principles of prudent antibiotic prescribing teaching in undergraduate students. Clin Microbiol Infect. 2015; 21(4):354-61.

14. Pulcini C, Williams F, Molinari N, et al. Junior doctors' knowledge and perceptions of antibiotic resistance and prescribing: a survey in France and Scotland. Clin Microbiol Infect. 2011; 17(1):80-7.

15. Mouton JW, Dudley MN, Cars O, et al. Standardization of pharmacokinetic/pharmacodynamic (PK/PD) terminology for anti-infective drugs: an update. J Antimicrob Chemother. 2005; 55(5):601-7.

16. Hsia Y, Lee BR, Versporten A, et al. Use of the WHO Access, Watch, and Reserve classification to define patterns of hospital antibiotic use (AWaRe): an analysis of paediatric survey data from 56 countries. Lancet Glob Health. 2019 ;7(7):e861-e871.

17. Barker Cl, Standing JF, Turner MA, et al. Antibiotic dosing in children in Europe: can we grade the evidence from pharmacokinetic/pharmacodynamic studies - and when is enough data enough? Curr Opin Infect Dis. 2012; 25(3):235-42.

\section{* This review triggers a debate on how to improve antimicrobial prescribing} considering methods to develop optimal dosage in children

18. Standing JF. Understanding and applying pharmacometric modelling and simulation in clinical practice and research. Br J Clin Pharmacol, 2017; 83(2):247-254.

\section{*This study provides an examaples of real-world PKPD use in clinical practice and}

\section{applied clinical research.}

17.19. Institute of Medicine (US) Committee on Clinical Research Involving Children . In: Ethical Conduct of Clinical Research Involving Children. Field MJ, Behrman RE, editors. National Academies Press (US); Washington (DC); 2004. [Accessed 25 July 2019]. Available from: https://www.ncbi.nlm.nih.gov/books/NBK25557/

20. Laughon MM, Benjamin DK Jr, Capparelli EV, et al. Innovative clinical trial design for pediatric therapeutics. Expert Rev Clin Pharmacol. 2011;4(5):643-52.

\section{*This article discussess the historical challenges in clinical trials in paediatric}

\section{population.}

18.21. Dykstra K, Mehrotra N, Tornoe CW, et al. Reporting guidelines for population pharmacokinetic analyses. J Pharmacokinet Pharmacodyn. 2015;42(3):301-14.

19.22. Byon W, Smith MK, Chan P, et al. Establishing best practices and guidance in population modeling: an experience with an internal population pharmacokinetic analysis guidance. CPT Pharmacometrics Syst Pharmacol. 2013;2:e51. 20.23. Kanji S, Hayes M, Ling A, et al. Reporting Guidelines for Clinical Pharmacokinetic Studies: The ClinPK Statement. Clin Pharmacokinet. 2015; 54(7):783-95. 
529 530

21.24. Pansa P, Hsia Y, Bielicki J, et al. Evaluating Safety Reporting in Paediatric Antibiotic Trials, 2000-2016: A Systematic Review and Meta-Analysis. Drugs 2018; 78(2):231-244.

25. McMullan BJ, Andresen D, Blyth CC, et al. Antibiotic duration and timing of the switch from intravenous to oral route for bacterial infections in children: systematic review and guidelines. Lancet Infect Dis. 2016; 16(8):e139-52.

*This review provides recommendations on antiboitic duration and timing of switching between formulations for children.

22.26. United Nations. Population Division: World Popilation Prospects 2019.

[Accessed 23 Aug 2019], available from: https://population.un.org/wpp/

\section{European Medicines Agency. Guideline on the evaluation of medicinal products} indicated for treatment of bacterial infections. 2011. [Accesed 07 Nov 2019]. available from:

https://www.ema.europa.eu/en/documents/scientific-guideline/guideline-evaluationmedicinal-products-indicated-treatment-bacterial-infections-revision-2 en.pdf 23.28. EUCAST. European society of clinical microbiology and infectious diseases. [Accessed 16 Aug 2019]; available from: http://www.eucast.org/ 
541

542

543 Table 1. Number of studies and country

\begin{tabular}{|c|c|c|}
\hline Drug & $\begin{array}{c}\text { Total } \\
\text { number of } \\
\text { studies* }^{*}\end{array}$ & Country (no. of studies) \\
\hline Amikacin & 22 & $\begin{array}{l}\text { Belgium (6), Canada (1), China (1), France (3), } \\
\text { Germany (1), Greece (1), Israel (1), Italy (1), New Zealand (1), } \\
\text { South Africa (2), South Korea (1), USA (3), Netherlands (1) }\end{array}$ \\
\hline $\begin{array}{l}\text { Amoxicillin } \\
\text { Ampicillin }\end{array}$ & $\begin{array}{c}8 \\
10\end{array}$ & $\begin{array}{l}\text { Australia (1), Brazil (1), Germany (1), Netherlands (3), USA (2) } \\
\text { Japan (1), USA (8), Uruguay (1) }\end{array}$ \\
\hline $\begin{array}{l}\text { Azithromycin } \\
\text { Benzathine benzylpenicillin }\end{array}$ & $\begin{array}{c}11 \\
1\end{array}$ & $\begin{array}{l}\text { Costa Rica (1), Saudi Arabia (1), Sub-Saharan Africa (1), USA (8) } \\
\text { USA (1) }\end{array}$ \\
\hline Benzylpenicillin & 5 & Estonia (2), Ethiopia (1), Netherlands (1), Uruguay (1) \\
\hline Cefalexin & 2 & Canada (1), USA (1) \\
\hline Cefazolin & 5 & Belgium (2), Japan (2), USA (1) \\
\hline Cefixime & 1 & Greece (1) \\
\hline Cefotaxime & 12 & Australia (1), France (3), Netherlands (1), UK (1), USA (6) \\
\hline Ceftriaxone & 6 & Switzerland (2), USA (3), Kenya (1) \\
\hline Chloramphenicol & 10 & $\begin{array}{l}\text { Ethiopia (1), Kenya (1), Mexico (1), Philippines-The Gambia (1), } \\
\text { UK (2), USA (4) }\end{array}$ \\
\hline Ciprofloxacin & 10 & $\begin{array}{l}\text { Finland (2), France (2), Germany (1), Kenya (1), South Africa (1), } \\
\text { UK (2), USA (1) }\end{array}$ \\
\hline Clarithromycin & 1 & USA (1) \\
\hline Clindamycin & 5 & USA (5) \\
\hline Cloxacillin & 1 & Canada (1) \\
\hline Co-amoxiclav & 7 & Belgium (1), Switzerland (2), UK (2), USA (2) \\
\hline Gentamicin & 62 & $\begin{array}{l}\text { Australia (2), Bangladesh (1), Canada (6), Chile (2), Czech } \\
\text { Republic (1), Denmark (1), Ireland (1), Israel (1), Japan (1), Kenya } \\
\text { (2), Mexico (1), Netherlands (7), Portugal (1), South Asia: India \& } \\
\text { Bangladesh (1), Spain (5), Sweden (1), Switzerland (1), Thailand } \\
\text { (1), UK (4), USA (22) }\end{array}$ \\
\hline Meropenem & 16 & $\begin{array}{l}\text { Estonia (1), Italy (1), Japan (2), Netherlands (2), Czech Republic } \\
\text { (1), Thailand (1), USA (9) }\end{array}$ \\
\hline Metronidazole & 7 & Australia (1), Canada (1), India (1), Mexico (1), UK (1), USA (1) \\
\hline Phenoxymethylpenicillin & 1 & Ethiopia (1), Kenya (1) \\
\hline Piperacillin-tazobactam & 9 & Belgium (1), China (1), France (1), USA (6) \\
\hline Procaine penicillin & 1 & Ethiopia (1) \\
\hline Trimethoprim-sulfamethoxazole & 6 & Chile (1), Israel (1), Mexico (1), USA (3) \\
\hline Vancomycin & 48 & $\begin{array}{l}\text { Belgium (1), Canada (4), Egypt (1), France (6), Iran (1), Israel (1), } \\
\text { Japan (1), Jordan (1), Malaysia (1), Netherlands (3), Portugal (1), } \\
\text { South Korea (1), Spain (1), Turkey (1), UK (1), USA (23) }\end{array}$ \\
\hline
\end{tabular}

${ }^{*}$ The total number of the studies does not add up to 262 as some studies covered more than one drug 
545 
Figure 1. Study selection flow chart

돈

Records identified through database searching

$$
(n=593)
$$

Additional records identified through other sources

$$
(n=138)
$$

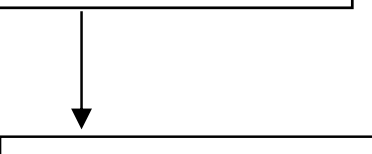

Records after duplicates removed

$$
(n=589)
$$

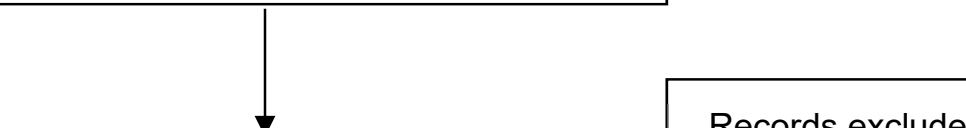

Records excluded based on titles and abstracts

$$
(n=244)
$$

Full-text articles excluded, with reasons

35 not relevant

20 no paediatric data

19 no PKPD data

8 reviews

1 could not be obtained

Studies included in the systematic review

$$
(n=262)
$$


Table 2. General description of included studies per drug

\begin{tabular}{|c|c|c|c|c|c|}
\hline Drug & $\begin{array}{l}\text { No. of } \\
\text { studies* }^{*}\end{array}$ & $\begin{array}{l}\text { Publication } \\
\text { years }\end{array}$ & $\begin{array}{l}\text { Sample } \\
\text { size }\end{array}$ & $\begin{array}{l}\text { Population } \\
\text { age }\end{array}$ & $\begin{array}{l}\text { Route of } \\
\text { administration }\end{array}$ \\
\hline Amikacin & 22 & $1975-2014$ & $9-205$ & $0 d-17 y$ & IV, IM \\
\hline Amoxicillin & 8 & $1980-2007$ & $17-150$ & $24 w-16 y$ & IV, PO \\
\hline Ampicillin & 10 & $1967-2018$ & $3-131723$ & $0 d-14 y$ & IV, IM, PO \\
\hline Azithromycin & 11 & $1993-2015$ & $10-179$ & $<72 \mathrm{~h}-16 \mathrm{y}$ & IV, PO \\
\hline Benzathine benzylpenicillin & 1 & 1982 & 26 & $1.8-10.7 y$ & IM \\
\hline Benzylpenicillin & 5 & $1995-2018$ & $13-37$ & $1 d-14 y$ & IV \\
\hline Cefalexin & 2 & $1982-2013$ & $12-20$ & $2 m-16 y$ & PO \\
\hline Cefazolin & 5 & $1988-20174$ & $5-56$ & $1 d-10 y$ & IV \\
\hline Cefixime & 1 & 1996 & 6 & $6-13 y$ & $\mathrm{PO}$ \\
\hline Cefotaxime & 12 & $1981-2018$ & $12-100$ & $1 d-18.7 y$ & IV, IM \\
\hline Ceftriaxone & 6 & $1982-2017$ & $10-80$ & $1 d-70 m$ & IV \\
\hline Chloramphenicol & 10 & $1980-2005$ & $14-81$ & $<7 d-13 y$ & IM, IV \\
\hline Ciprofloxacin & 10 & $1992-2014$ & $10-150$ & $1 d-24 y$ & IV, PO \\
\hline Clarithromycin & 1 & 1992 & 24 & $6 m-10 y$ & PO \\
\hline Clindamycin & 5 & $1984-2017$ & $40-220$ & $1 d-20 y$ & IV, PO \\
\hline Cloxacillin & 1 & 1990 & 14 & $0.5-15 y$ & IV \\
\hline Co-amoxiclav & 7 & $1983-2015$ & $11-50^{*}$ & $<2 y-18 y$ & IV, PO \\
\hline Gentamicin & 62 & $1971-2017$ & $7-1854$ & $0 d-18 y$ & IM, IV \\
\hline Meropenem & 16 & $1995-2017$ & $1-188$ & $23 \mathrm{w}$ to $17.3 \mathrm{y}$ & IV \\
\hline Metronidazole & 7 & $1982-2017$ & $11-68$ & $1 d-45 m$ & IV \\
\hline Phenoxymethylpenicillin & 1 & 1995 & 49 & $7 m-6.5 y$ & $\mathrm{PO}$ \\
\hline Piperacillin-tazobactam & 9 & $1994-2017$ & $12-746^{\star *}$ & $1 d-15 y$ & IV \\
\hline Procaine penicillin & 1 & 1995 & 18 & $7 m-6.5 y$ & IM \\
\hline Trimethoprim-sulfamethoxazole & 6 & $1975-2018$ & $4-153$ & $<3 d-16 y$ & IV \\
\hline Vancomycin & 48 & $1986-2017$ & $5-702$ & $0 \mathrm{~d}-18 \mathrm{y}$ & IV \\
\hline
\end{tabular}

d: day; m: month; y: year; w: week; h: hour; PO: by mouth; IV: intravenous; IM: intramuscular

${ }^{*}$ The total number of the studies does not add up to 262 as some studies covered more than one drug 
Table 3. Suggested doses for the WHO Access and Watch antibiotics groups for the treatment of most common conditions in children

\begin{tabular}{|c|c|c|c|c|}
\hline \multirow[b]{2}{*}{ Antibiotic } & \multicolumn{2}{|c|}{ Neonates } & \multicolumn{2}{|c|}{ Children } \\
\hline & $\begin{array}{l}\text { Total daily dose } \\
\text { (mg/kg/day) }\end{array}$ & $\begin{array}{l}\text { Dosing frequency } \\
\text { (divided every } \mathrm{x} \text { hours) }\end{array}$ & Total daily dose (mg/kg/day) & $\begin{array}{l}\text { Dosing frequency } \\
\text { (divided every } \mathrm{x} \text { hours) }\end{array}$ \\
\hline Amikacin & $15-20$ & Every 24 hours & $15-20$ & Every 24 hours \\
\hline Amoxicillin & $80-100$ & Every 12 hours & $80-100$ & Every 12 hours \\
\hline Amoxicillin + clavulanic acid & $\begin{array}{l}65 \text { - } 100 \text { (of amoxicillin } \\
\text { component) }\end{array}$ & Every 12 hours & $\begin{array}{l}65 \text { - } 100 \text { (of amoxicillin } \\
\text { component) }\end{array}$ & Every 12 hours \\
\hline Ampicillin & $100-150$ & Every $8-12$ hours & $80-100$ & Every $6-12$ hours \\
\hline Azithromycin & 10 & Every 24 hours & $10-20$ & Every 24 hours \\
\hline Benzathine benzylpenicillin & See syphilis guidelines* & & See syphilis guidelines* & \\
\hline Benzylpenicillin & $80-100$ & Every $8-12$ hours & $80-100$ & Every 6 - 12 hours \\
\hline Cefalexin & $50-100$ & Every $12 \underline{8}$ hours & $50-100$ & Every $12 \underline{8}$ hours \\
\hline Cefazolin & $50-100$ & Every 8 - 12 hours & $50-100$ & Every 8 - 12 hours \\
\hline Cefixime & No suggestion & - & 8 & Every 12 - 24 hours \\
\hline \multirow[t]{2}{*}{ Cefotaxime } & 50 & Every $6-12$ hours & $100-150$ & Every $6-12$ hours \\
\hline & (up to 200 in severe infection) & & (up to 200 in severe infection) & \\
\hline Ceftriaxone & 50 & Every 24 hours & $50-100$ & Every 24 hours \\
\hline Ceftazidime & $90-150$ & Every 8 hours & $90-150$ & Every 8 hours \\
\hline Chloramphenicol & No suggestion & - & $50-100$ & Every 6 - 8 hours \\
\hline Ciprofloxacin & $20-30$ & Every 12 hours & $20-30$ & Every 12 hours \\
\hline Clarithromycin & 15 & Every 12 hours & 15 & Every 12 hours \\
\hline Clindamycin & $10-20$ & Every 6 - 8 hours & $20-40$ & Every 6 - 8 hours \\
\hline Cloxacillin & $50-100$ & Every 12 hours & $100-200$ & Every 6 hours \\
\hline
\end{tabular}




\begin{tabular}{|c|c|c|c|c|}
\hline \multirow[b]{2}{*}{ Antibiotic } & \multicolumn{2}{|c|}{ Neonates } & \multicolumn{2}{|c|}{ Children } \\
\hline & $\begin{array}{l}\text { Total daily dose } \\
\text { (mg/kg/day) }\end{array}$ & $\begin{array}{l}\text { Dosing frequency } \\
\text { (divided every } x \text { hours) }\end{array}$ & Total daily dose (mg/kg/day) & $\begin{array}{l}\text { Dosing frequency } \\
\text { (divided every } \mathrm{x} \text { hours) }\end{array}$ \\
\hline Doxycycline & No suggestion & & $2-4$ & Every 12 - 24 hours \\
\hline Gentamicin & 5 & Every 24 hours & 7 & Every 24 hours \\
\hline Meropenem & 60 & Every 8 hours & 60 & Every 8 hours \\
\hline Metronidazole & $20-40$ & Every 8 - 12 hours & $20-40$ & Every 8 - 12 hours \\
\hline Nitrofurantoin & No suggestion & - & 4 & Every $6-12$ hours \\
\hline Phenoxymethylpenicillin & No suggestion & - & $100-200$ & Every $6-12$ hours \\
\hline Piperacillin-tazobactam & $\begin{array}{l}300 \text { - } 400 \text { (of piperacillin } \\
\text { component) }\end{array}$ & Every 6 - 12 hours & $\begin{array}{l}300 \text { - } 400 \text { (of piperacillin } \\
\text { component) }\end{array}$ & Every 6 - 12 hours \\
\hline Procaine benzylpenicillin & See syphilis guidelines* & & See syphilis guidelines* & \\
\hline Spectinomycin & No suggestion & & No suggestion & \\
\hline $\begin{array}{l}\text { Trimethoprim + } \\
\text { sulfamethoxazole }\end{array}$ & No suggestion & & $\begin{array}{l}\text { 8-12 (of trimethoprim } \\
\text { component) }\end{array}$ & Every 12 hours \\
\hline Vancomycin & $40-60$ & Every 12 hours & $40-60$ & Every 6 -12 hours \\
\hline
\end{tabular}

Doses of beta-lactams may be doubled in treatment of meningitis.

*Syphilis guidelines (2016) available at https://www.who.int/reproductivehealth/publications/rtis/syphilis-treatment-guidelines/en/

No suggestion: it is not used for the included age group. 
Supplementary Table 1. Antibiotics included in the Access and Watch groups of the 2019 WHO EMLclist

\begin{tabular}{ll}
\hline Key-Access group & Watch group \\
\hline Amikacin & Azithromycin \\
Amoxicillin & Cefixime \\
Amoxicillin + clavulanic acid & Cefotaxime \\
Ampicillin & Ceftriaxone \\
Benzathine benzylpenicillin & Ciprofloxacin \\
Benzylpenicillin & Ceftazidime* \\
Cefalexin & Cefuroxime* \\
Cefazolin & Clarithromycin \\
Chloramphenicol & Piperacillin + tazobactam \\
Clindamycin & Meropenem \\
Cloxacillin & Vancomycin \\
Doxycycline & \\
Gentamicin & \\
Metronidazole & \\
Nitrofurantoin & \\
Phenoxymethylpenicillin & \\
Procaine benzylpenicillin & \\
Spectinomycin & \\
Sulfamethoxazole + trimethoprim &
\end{tabular}

Supplementary Figure 1. Search terms used in each literature search 
Appropriate international non-proprietary drug name

\section{AND}

(pharmacology OR pharmacokinetic ${ }^{\star}$ OR pharmacodynamics $\left.{ }^{\star}\right) . t w$.

AND

Exp administration, oral/

(Oral\$ OR per os or po).tw.

Infusion, intravenous/

injections, intravenous/

injections, intramuscular/

(intravenous\$ OR intra-venous\$ OR iv OR intramuscular\$

$O R$ intra-muscular\$ or im OR parenteral\$).tw.

\section{AND}

exp newborn/ OR infant/ OR exp child/ OR adolescent/

(infant* OR child* OR newborn* OR babies or neonate ${ }^{\star}$ or preterm ${ }^{\star}$

or premature ${ }^{\star}$ or full-term ${ }^{\star}$ or boys or girls or adolescen ${ }^{\star}$ or paediatric ${ }^{\star}$

or pediatric ${ }^{\star}$, teen ${ }^{\star}$, young child preschool child $\left.{ }^{\star}\right)$.tw.

Supplementary table 2. List of reported indications and dosing recommendation from the 262 included studies. 